\title{
COMIDA E CULTURA: ANTROPOLOGIA DA ALIMENTAÇÃO EM COMUNIDADES RURAIS DO PARANÁ
}

\author{
Stefany Ferreira Feniman, Marivânia Conceição Araujo \\ Universidade Estadual de Maringá - PGC/UEM. Mestrado em Ciências Sociais, Maringá, PR. e-mail: \\ stefanyffeniman@hotmail.com
}

\section{RESUMO}

Este artigo se dedica à análise dos hábitos alimentares de três comunidades rurais do noroeste paranaense, Brasil, de agricultura familiar. São elas: Pirapitinga, Marajó e Santa Rita. Para tal, utilizase o aporte teórico da antropologia dos alimentos, propondo uma reflexão de cunho qualitativo, a partir da função social, relacionada ao conceito de cultura, cujo pressuposto é que as construções culturais determinam o que é comestível em cada comunidade. Entende-se que o comportamento relativo à comida é um eficaz instrumento para a compreensão da dinâmica de relações sociais existentes, revelando fatores culturais, históricos, econômicos, ambientais. Com metodologia etnográfica e análise de 45 entrevistas semi-estruturadas, buscamos a compreensão e análise do processo de construção identitária, da alimentação, sua estrutura, organização e valores.

Palavras-chave: Antropologia e Alimentação, Comunidades Rurais, Comida, Identidade.

\section{FOOD AND CULTURE: ANTHROPOLOGY OF FOOD IN RURAL COMMUNITIES OF PARANÁ}

\begin{abstract}
This article is dedicated to the analysis of the food habits of three rural communities in northwestern Paraná, Brazil, family farming, they are: Pirapitinga, Marajó and Santa Rita. For this, we use the theoretical contribution of the anthropology of food, proposing a reflection of a qualitative nature, from the social function, related to the concept of culture, whose assumption is that cultural constructions determine what is edible in each community. It is understood that the relative behavior of food is an effective tool for understanding the dynamics of social relations, showing cultural, historical, economic and environmental factors. An ethnographic methodology and analysis of 45 semi-structured interviews, we seek the understanding and analysis of the process of identity construction, supply, its structure, organization and values.
\end{abstract}

Keywords: Anthtopology and feed, Rural Communities, Food, Identity. 


\section{INTRODUÇÃO}

Pensar a alimentação perpassa pensar sua dicotomia funcional, por um lado a alimentação apresenta uma função fisiológica, relacionada ao conceito de natureza, correspondente à necessidade de ingestão de nutrientes para sobrevivência e, por outro, a função social, que se relaciona ao conceito de cultura. Esta abordagem vem sendo tema crescente de estudos antropológicos, pois são as construções culturais que determinam o que é comestível em cada sociedade e como cada alimentos deve ser ingerido (TEMPASS, 2005).

Alimento e comida são diferenciados pela teoria antropológica: enquanto o primeiro consiste em qualquer nutriente biologicamente ingerível, a comida resulta de uma escolha, seleção, realizada culturalmente do que pode ser comestível ou não, permeando um processo de aceitação cultural (FISCHLER, 2001).

É assim que os hábitos alimentares são reveladores da dinâmica das relações sociais existentes e consistem em um eficaz instrumento para a reflexão e compreensão sobre fatores sociais, culturais, ecológicos, econômicos e históricos, associados às redes de representações, simbolismos e rituais da sociedade, como discorre Mártin Tempass (2005):
A alimentação é um traço cultural que expressa relações e pertencimentos grupais e define identidades. Além de boa para comer, a comida também é boa para representar e significar. A origem e as características sócio-culturais de um determinado grupo podem ser reconhecidas por meio do estudo sobre a maneira de comer, o cheiro, a aparência e o sabor dos alimentos por ele consumidos. (TEMPASS, 2005, p.88)

A diversidade de sistemas culturais, explica grande parte dos diferentes e comparados comportamentos relativos à comida. É culturalmente que diversos sinais diacríticos são formulados para classificar os alimentos, tais como em bons ou ruins, saudáveis ou nocivos, proibidos ou autorizados, para o cotidiano ou para festas, de crianças ou de adultos, de homens ou de mulheres. Isto sinaliza também para a grande capacidade que a comida possui de evocar sentimentos, despertar emoções.

Sidney Mintz (MINTZ, 2001) afirma que a rotina do comer pode ser um dos traços mais persistentes dentro de uma cultura, mas a dinâmica desse alimentar-se está sujeita as alterações. Em consonância, Tempass (2005) afirma que "mesmo sendo a alimentação um traço cultural de forte permanência, a 
dinamicidade das culturas e, conseqüentemente, das cozinhas pode gerar alterações em seus pratos típicos ou substituílos por outros." (TEMPASS, 2005, p.98)

A manipulação de alimentos ocorre a partir de escolhas específicas, imersas em um sistema cultural e simbólico no qual o indivíduo está inserido. A determinação de cardápios, as técnicas utilizadas no preparo e cocção, a ingestão sob circunstâncias específicas, requerem um conhecimento social acumulado sobre a comida, integram um processo ritualizado sobre o "comer", com uma série de etapas e sucessão de ações.

O que um grupo "come" não é uma aleatoridade. Nas comunidades rurais abordadas neste trabalho, visualiza-se o preparo de receitas tais como risoto de frango caipira, pão caseiro assado na folha de bananeira, pastel perorrê, virado de banana, polenta com cambuquira. Estas e outras infindáveis receitas são exemplos de como os alimentos são preparados e consumidos sob uma forma culturalizada.

Afirma o antropólogo Mintz que "Dificilmente outro comportamento [o ato de comer] atrai tão rapidamente a atenção de um estranho como a maneira que se come: o quê, onde, como e com que freqüência comemos, e como nos sentimos em relação à comida" (MINTZ, 2001, p.31), sobre o relevante interesse dos estudos antropológicos, desde o seu início como ciência, pelos comportamentos centrados na comida.

Por isso a alimentação se constitui como um forte elemento de construção identitária, uma vez que este processo ocorre no estranhamento e confronto sobre determinada característica de um grupo. Um costume alimentar salta aos olhos de um observador externo àquela prática, como um potencial diacrítico marcante.

Esta temática teve de conquistar espaço como papel central nas pesquisas. Em sua trajetória, estudos publicados entre as décadas e 30 e 60 do século passado, até mesmo 80 , não registram muitas monografias deste tipo, talvez porque de acordo ainda com a visão de Sidney Mintz:

A comida e sua preparação eram vistas como trabalho de mulher e a maioria dos antropólogos fosse composta por homens; ou porque o estudo da comida fosse considerado prosaico e pouco importante, comparado ao da guerra, da sucessão na chefia, ou da mágica e da religião. (MINTZ, 2001, p.32)

Essa realidade nos estudos começou a mudar a partir do aumento do número de pesquisadores e antropólogos passaram a iluminar temas mais relacionados com 
atividades tradicionalmente femininas.

Também ao surgimento de um comércio global de alimentos, que fez com que os autores se voltassem a sociedades de pequeno porte e ao papel de destaque que a comida sempre desempenhou na trajetória do sistema capitalista. As pesquisas que surgiram então passaram a enfatizar novos alimentos e sistemas de distribuição globais.

O adágio popular "os homens são o que comem", aplicado na realidade empírica deste trabalho, vincula-se à concepção que os pequenos agricultores pesquisados possuem das noções de saúde, de sua identidade e de suas memórias coletivas:

A comida 'entra' em cada ser humano. A intuição de que se é de alguma maneira substanciado - 'encarnado' a partir da comida que se ingere pode, portanto, carregar consigo uma espécie de carga moral. Nossos corpos podem ser considerados o resultado, o produto, de nosso caráter que, por sua vez, é revelado pela maneira como comemos. (MINTZ, 2001, p.32)

A comida faz esse movimento de ascensão ao auge da intimidade humana, introduzida via oral, se torna então propiciadora e, sobretudo, integrante da existência humana. As virtudes sociais atribuídas às comidas são incorporadas e estas proporcionam ao homem que se torne aquilo que comeu. É por isto que a preocupação com a produção de uma agricultura orgânica, que não se utiliza de agrotóxicos e que assegura confiança ao alimento, vem sendo preocupação crescente. A preocupação com a quantidade de açúcar ingerido pelas crianças em alimentos e bebidas industrializadas também é outro exemplo de como o provérbio popular se aplica no dia-a-dia e faz com que os pais busquem a valorização de itens locais, produzidos segura e conscientemente.

Utilizando-se desta bagagem teórica da antropologia da alimentação e compartilhando da mesma lógica o projeto extensionista "ECOALIM - Incubação de Empreendimentos Econômicos Solidários: Hábitos alimentares e culturais em comunidades rurais", vinculado ao Núcleo e Incubadora de Empreendimentos Econômicos Solidários UNITRABALHO/UEM, responsável pela coleta de dados necessários a este trabalho, buscou-se explorar e compreender a relação entre o alimento e a cultura camponesa. O viés adotado enfatizou o aspecto cultural, considerando que atuar apenas com base no aspecto econômico de um grupo não é suficiente, pois a cultura é a responsável por dar significados, o sentimento de pertencimento, valorização e coesão no grupo. 
Como as comidas são associadas a povos em particular, e muitas delas são consideradas

inequivocamente nacionais, lidamos freqüentemente com questões relativas à identidade. (MINTZ, 2001, p.34)

Considerando a afirmativa de Sidney Mintz, em "Comida e Antropologia - uma breve revisão", pode-se perceber que a identidade construída pelas três populações rurais estudadas é um conceito-chave pertinente ao trabalho, uma vez que a identidade dos pequenos agricultores é construída pelo estilo de vida rural, e a composição da alimentação, das mesas, do que se come, é fundamental para entender e apreender o sistema alimentar do grupo.

O trabalho foi realizado com pequenos produtores da agricultura familiar em três comunidades rurais diferente do Paraná: comunidade rural de Pirapitinga, localizada no município de Nova Esperança; assentamento de reforma agrária Marajó, localizado no município de Quinta do Sol; e assentamento de reforma agrária Santa Rita, localizado no município de Peabiru. O conceito de "agricultor familiar" aqui utilizado alinha-se com Altmann (2002), citado por SOUZA et al. (2011), compreendido como aquele que explora parcialmente a terra na condição de proprietário, assentado, posseiro, arrendatário ou parceiro Como condicionais deve enquadrar-se ainda nos seguintes critérios:

Utiliza o trabalho direto, seu e de sua família, podendo ter, em caráter complementar, até dois empregados permanentes e contar com ajuda de terceiros, quando a natureza sazonal da atividade agropecuária o exigir; não detenha, a qualquer título, área superior a quatro módulos fiscais, quantificados segundo a legislação em vigor; tenha, no mínimo, $80 \%$ da renda familiar bruta anual originada da exploração agropecuária, pesqueira e/ou extrativa; resida na propriedade ou em aglomerado rural ou urbano próximo. (ALTMANN apud SOUZA et al., 2011, p. 94)

Pirapitinga é uma comunidade rural localizada no município de Nova Esperança, na meso-região norte central paranaense, possui uma extensão de 1.851, 58 hectares, partilhada por 30 famílias. A comunidade se destaca pela produção significativa de casulos verdes $^{1}$ do Paraná, $46 \%$ dos produtores rurais cultivam amoreiras, que são utilizadas na alimentação do bicho da seda, enquanto que 
$12 \%$ se dedicam, primordialmente, ao plantio do café ${ }^{2}$.

Marajó é um assentamento de reforma agrária, situado no município de Quinta do Sol, no centro ocidental paranaense, existe desde o ano de 2000 , possui uma extensão de 938,48 hectares e abriga 65 famílias. As atividades primárias são os plantios de feijão, milho, soja, mandioca, hortaliças e pecuária leiteira. O assentamento também conta com uma associação de mulheres denominada AMAM Associação de Mulheres do Assentamento Marajó, que produz pães, doces e salgados. A idéia da associação surgiu em 2006 a partir de reuniões nas quais as mulheres realizam atividades de grupo e partilhavam entre si alimentos como café, chimarrão, bolos, bolachas. Com o apoio financeiro de instituições governamentais e recursos disponíveis no próprio assentamento, as mulheres realizaram cursos de especialização em panificação.

O assentamento Santa Rita, também localizado na região centro ocidental paranaense, pertence ao município de Peabiru, conta com uma área total de $1.713,50$ hectares dividida em 90 famílias. No início do acampamento havia 120 famílias que lutaram pela terra. O grupo era reconhecido como

\footnotetext{
${ }^{2}$ Em: FENIMAN, Stefany F.; Alvez, Maria A. Hábitos Alimentares e a dinâmica das relações sociais campesinas. Revista UNIFAMMA, Maringá, v. 11, n. (esp.), p. 55, jun. 2012.
}

acompanhamento da Baia. Em 1998, as famílias ocuparam finalmente a fazenda da Baia sem grandes conflitos. Atualmente, as principais atividades da comunidade são a produção pecuniária de leite, cultivo de maracujá orgânico, leguminosas e hortaliças.

O número de famílias totaliza 230, nos dois assentamentos trabalhados, estão assentadas pelo INCRA entre 15 e 20 anos. Em comum elas possuem o modo de desenvolvimento baseado na agricultura familiar, importante tanto para a produção de alimentos, como para a geração de trabalho no meio rural. Hoje, a agricultura familiar responde por $70 \%$ dos alimentos consumidos pelos brasileiros.

Enquanto permanecem no campo, é dele que os produtores retiram os alimentos que necessitam para viver fisiológica e culturalmente, consiste não somente num local de plantio e produção meramente, mas principalmente, uma raiz que os liga ao solo fértil de sua história, como sujeitos localizados, dotados de uma identidade e ligados a um passado de ascendência também campesina.

$$
\text { O vínculo entre a Universidade }
$$

Estadual de Maringá, Paraná, Brasil, e mais especificadamente, da Incubadora UNITRABALHO/UEM e as três comunidades tornou-se possível devido ao interesse desses produtores em procurar e solicitar a 
assistência da universidade. A presente pesquisa teve como objetivo promover 0 resgate e valorização da identidade e da cultura camponesa, por meio da análise e compreensão das relações sociais entre o alimento e a cultura.

\section{MEDODOLOGIA}

A pesquisa qualitativa exposta neste artigo foi conduzida sob um delineamento descritivo e explicativo. $O$ procedimento metodológico pautou-se pela etnografia, com um conjunto de técnicas que consistiu na observação participante ao longo de um período de 12 meses, de 2011 à 2012, com registros em diário de campo, realização de entrevistas e a obtenção de dados por meio da aplicação de 45 questionários semiestruturados, acerca dos hábitos alimentares, no que tange a produção, preparação, consumo, partilha, regras sociais e de etiqueta, valores, preferências, proibições e classificações. A análise dos questionários teve como embasamento a Antropologia da alimentação.

Pautando-se por uma etnografia, que pleonasticamente afirma seu caráter qualitativo, esta pesquisa foi conduzida sem a intermediação de comitê de ética. O procedimento científico orientado seguiu as conformidades de Sarti e Duarte (2013):
Nessa interlocução constitutiva do trabalho antropológico e da produção do conhecimento nesse campo, as questões éticas emergem necessariamente e são postas em movimento, resultado de negociações constantes entre os distintos agentes sociais envolvidos, observadores e observados, fazendo de sua regulamentação, por definição, um campo de tensões que, uma vez configurado, clama por sair do lugar, em permanentes revisões. De outro modo, corre-se o risco da 'burocratização da ética'. (SARTI; DUARTE, 2013, p. 10).

A partir da prerrogativa de Claude LeviStrauss (1976, p.172), em sua célebre frase "As espécies naturais não são escolhidas apenas porque são boas para comer, mas porque são boas para pensar", e também do método descritivo acerca desse "comer" no estilo de vida rural, obtem-se a possibilidade de análise das relações sociais que se estabelecem para além do imediatismo, em uma visão mais ampla, sobre os papéis sociais que cada indivíduo desempenha nas pequenas comunidades estudadas de agricultores familiares.

O questionário aplicado obedecia a um roteiro elaborado com 18 perguntas acerca dos hábitos alimentares e culturais. Entretanto, a 
abordagem realizada foi dialogada, o que implicou que informações foram obtidas com o acréscimo de outras perguntas, intervenções, sem necessariamente, seguir rigorosamente ao roteiro, mas sim, seguindo o ritmo natural com que as conversas fluíam, tendo o roteiro, apenas como base.

As entrevistas com os interlocutores foram realizadas em profundidade, dentro de um complexo antropológico que propõe o método da etnografia. Os dados coletados foram registrados em um diário de campo, reproduzindo falas originais dos entrevistados, bem como as impressões do entrevistador acerca do diálogo.

A etapa seguinte foi transcrever essas anotações para o formato digital, a fim de serem tabuladas e facilitar o manuseio das informações obtidas. O método escolhido para interpretação das entrevistas trabalhou com a análise de conteúdo, no qual as respostas fornecidas pelos produtores rurais, suas falas e expressões nativos, já transformados em formato textual, constituem o objeto de análise deste artigo. O objetivo é fomentar a discussão acerca do contexto de consumo alimentar rural em estudo e a identificação de seus valores e princípios inerentes.

Esta metodologia possibilita transparência e fidedignidade na interpretação acerca do conteúdo e visa à produção de sentidos e significados na variedade de respostas obtidas. Diante do fenômeno de preparação do alimentar-se este procedimento indica a maneira como o simbolismo é vivido pelos indivíduos, conforme as imagens de cada um em relação à perspectivas positivas ou negativas na rotina da vida rural aplicadas ao ato de comer.

Pretende-se aqui descrever e compreender os significados do preparo alimentar como um ritual para a transformação do alimento em comida. Entrando como aporte teórico, a bibliografia a ser utilizada para identificar as categorias é aquela que embasa a antropologia simbólica e a antropologia da alimentação.

O momento de pré-análise dos questionários, uma das fases de organização da Análise de Conteúdo, seguindo os passos preconizados por Bardin (1979), apontou, pela contagem da manifestação dos elementos textuais.

\section{RESULTADOS}

$\mathrm{Na}$ compreensão dos hábitos alimentares dos grupos rurais pesquisados, partiu-se do questionamento sobre quais os alimentos consumidos pela família. Com esse ponto de partida, obteve-se a base da alimentação cotidiana, do trivial no dia-a-dia. 
Foram mencionados 56 itens diferentes ${ }^{3}$ espontaneamente e a partir de então, as entrevistas desenvolveram-se com o objetivo de explorar ao máximo tais informações.

A dobradinha feijão e arroz, que compõe a base do cardápio dos brasileiros para o almoço e o jantar (BARBOSA, 2007), foi citada em $95 \%$ das entrevistas quando questionava os tipos de alimentos consumidos, seguida do consumo de carnes, em $83 \%$ dos casos. Neste percentual, 30\% citam o consumo de frango, $27 \%$ o consumo de carne suína e apenas $8 \%$ citam o consumo de peixe.

A produção da horta e do quintal é de fundamental importância, pois fornecem recursos à alimentação do dia-a-dia. É comum observar que os sítios das comunidades sempre dispõem de tipos variados de arvores frutíferas, com destaque para as cítricas, destinadas ao consumo doméstico. Da horta e do quintal, os produtores retiram boa parte dos itens alimentares do tipo temperos, legumes, verduras, saladas e frutas, deixando a necessidade de comprar nos estabelecimentos comerciais aqueles itens que não produzem com vigor. Há também relatos de doações e trocas entre os vizinhos ou parentes de uma mesma comunidade rural.
Utilizando as categorias nativas, o consumo de frutas apareceu em $67 \%$ das entrevistas, seguido do consumo de legumes (53\%) e verduras (51\%). A categoria "salada" apareceu em $35 \%$ pelos entrevistados, seguida da "mandioca", presente em 33\%. O pão, outro item com significativa repetição, ganhou frequência em $28 \%$ das entrevistas, destacado por alguns informantes como produto eminentemente caseiro. Entre $12 \%$ e $16 \%$ das entrevistas aparece o consumo de macarrão, ovos, batata e leite. Outros itens aparecem com menor ocorrência.

\footnotetext{
${ }^{3}$ Os termos alimentares aqui utilizados foram categorias alimentares atribuídas pelos próprios entrevistados 
Gráfico 1. "Itens alimentares consumidos": Pirapitinga, Marajó e Santa Rita - comunidades rurais do Paraná, 2012.

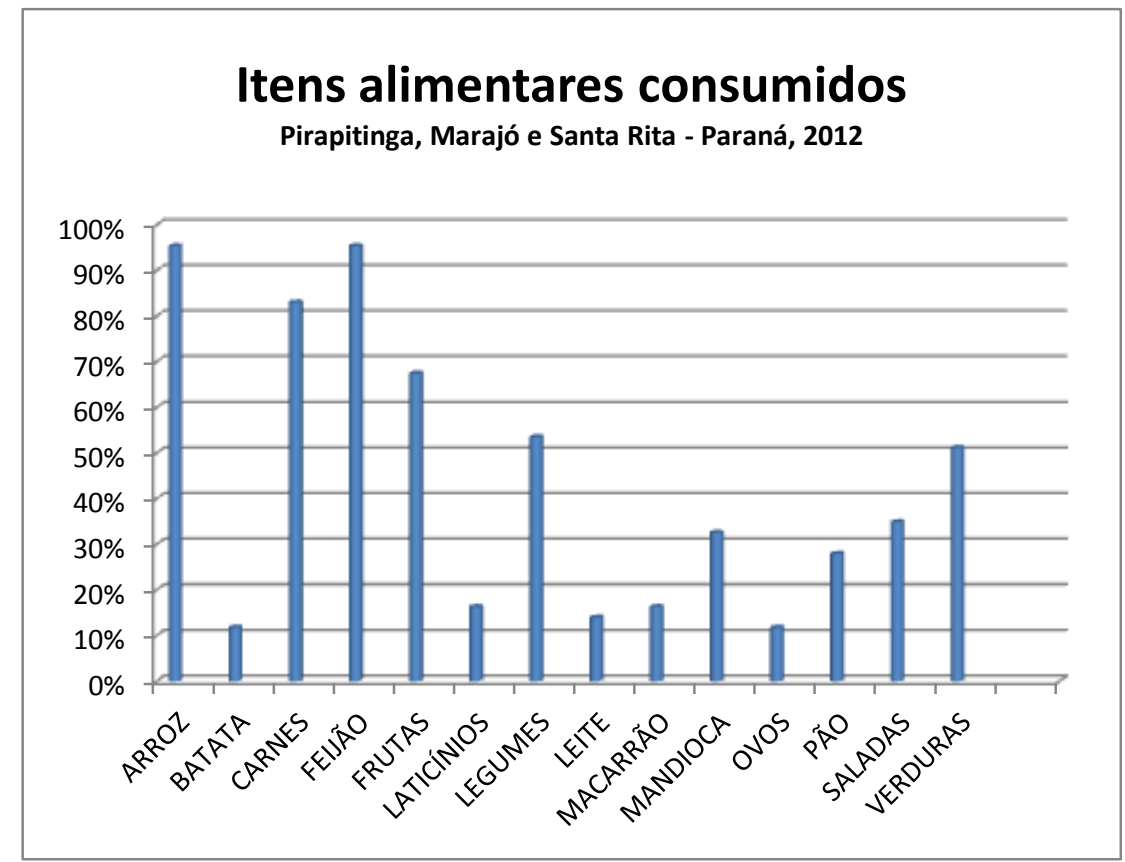

Fonte: autor

Os pratos culinários que compunham a mesa no passado e hoje por diversos motivos não estão mais igualmente presentes, ou sofreram alterações na forma de preparo somam o total de 61 receitas. Apenas $11 \%$ dos entrevistados não notaram ausência ou modificação na forma de se alimentar.

A forma de conservação da carne de porco também aparece com destaque como hábito que se modificou. Apontada em 15\% das entrevistas, antes a carne suína era conservada com o ritual de uma fritura em gordura também de porco, posteriormente coberta com a mesma gordura animal, no interior de uma lata de alumínio, com boa vedação, onde permanecia conservada por até doze meses. A carne bovina era salgada e pendurada em varal para secar ao sol.

Para os objetivos aos quais este artigo se dedica, os estudos refletem que para $54,54 \%$ dos pequenos agricultores há receitas que são preparadas apenas para os membros da família, e não em ocasiões de visitas. Esses casos acontecem quando uma receita é nova e será preparada pela primeira vez, para que passe primeiro pela avaliação dos familiares e obtenha-se a certeza de que agrada, e só 
depois possa ser elaborada em ocasiões de visita.

O preparo de ovos fritos ou mexidos para compor o cardápio da refeição, nas comunidades rurais também foi citado como uma exclusividade da família em casa, não deve ser servindo para receber pessoas de fora, até mesmo pela categorização como um prato típico de baixa classe social e desprestígio.

Por outro lado, $45,45 \%$ dos entrevistados responderam que não existe essa distinção entre o alimento preparado na casa, o que é preparado para um, todos comem, o que servido para a família, é servido também às visitas, com diferença apenas na quantidade, com o aumento das porções.

Os estudos na comunidade rural de Pirapitinga e nos assentamentos de reforma agrária Marajó e Santa Rita também registraram que os itens comprados no mercado somaram 236 respostas concedidas pelo total de entrevistados, considerando repetições. Enumerando-as sem repetições, as categorias registram 72 itens distintos. Destes, 37 categorias foram respondidas apenas uma vez, são itens como por exemplo biscoitos, bolo, chocolate, tipos específicos de verduras, tipos específicos de frutas, linguiça, pão, pizza, temperos específicos.
Foram 15 as categorias que apareceram duas vezes no total de respostas, correspondendo à batata, bolacha, enlatados, fermento, frios, industrializados, iogurte, leite, massa de tomate, extrato de tomate, molho de tomate $^{4}$, pimenta do reino, produtos de limpeza, refrigerante, tomate.

Quatro categorias compradas no mercado apareceram três vezes em relação ao total de respostas obtidas dos entrevistados: cebola, frutas, leite condensado e ovos. Alho, legumes, temperos e trigo ${ }^{5}$ apareceram quatro vezes. Carne de boi $^{6}$, farinha e verdura foram categorias mais recorrentes, citadas cinco vezes. A farinha de trigo e o sal, foram apontadas seis vezes pelos informantes no total de itens comprados. Outras duas categorias, carne e café, foram citadas nove vezes ao longo de todas as respostas, como itens comprados.

Os cinco itens mais populares vindos do mercado são o óleo, que aparece em 10 respostas, o açúcar, que aparece em 14

\footnotetext{
${ }^{4}$ Massa de tomate, extrato de tomate e molho de tomate foram contados como 3 categorias distintas, de acordo com a resposta espontânea que os entrevistados concederam. Cada uma delas aparece apenas 2 vezes ao longo de todo levantamento, correspondendo ao porcentual individual de $0,84 \%$.

${ }^{5}$ De acordo com os termos respondidos pelos entrevistados, trigo, farinha e farinha de trigo também foram divididos em três diferentes categorias alimentares. "Trigo" aparece em 4 respostas, correspondendo a 1,69\%. "Farinha" corresponde a 2,11\%, usada 5 vezes. Já "Farinha de trigo" corresponde a 2,54\%, tendo sido usada 6 vezes.

${ }^{6}$ Os itens "carne de boi" e "carne" também foram diferenciados em duas categorias distintas. O primeiro, aparece cinco vezes no total do levantamento, correspondendo a $2,11 \%$ de todas as respostas, e o segundo, mais geral, aparece nove vezes no total das respostas, atingindo $3,81 \%$.
} 
respostas, o macarrão citado 16 vezes, feijão citado 21 , e recorde nas respostas obtidas, o arroz, citado em 35 respostas, correspondendo a $14,83 \%$ do total de itens comprados.

Destacam-se os diferentes papéis que os agentes sociais desempenham em meio à comensalidade, com suas atribuições, comportamentos e significados. Ser mulher, em meio a esse processo, significa, por exemplo, se for mãe, ser a principal fonte responsável pela transmissão de conhecimentos sobre culinária para os filhos, ser também a única responsável pela compra dos itens alimentares em $41,46 \%$ dos casos, e ser ainda a única responsável pelo preparo da alimentação em $64,44 \%$ dos casos, desde a composição dos cardápios até a apresentação dos pratos, com o dever de conciliação sempre com os ingredientes e recursos que dispõem na casa.

O preparo da alimentação e da comida é feito pelo homem e pela mulher, juntos, em apenas $4,4 \%$ dos casos. Em 6,6\% entrevistas responderam que variam e ainda com esta mesma proporção, o preparo dos alimentos foi respondido que é feito pela mulher com a ajuda da filha. Pessoas que não responderam ou não souberam opinar somam 11,11\%,

Apenas em 6,6\% o homem é o único responsável pela alimentação, encarada como um hobby ou diversão. Nestes casos, as receitas predominantemente elaboradas são de carne assada, geralmente aos domingos e feriados. Comprova-se aqui, a forte divisão de trabalho por gênero, que não apresenta mudanças, se comparado aos relatos de passado mais longínquo descritos pelos agricultores e indo de encontro à outras etnografias e pesquisas.

\section{DISCUSSÃO}

O fato de os agricultores possuírem seus próprios plantios e produções para consumo próprio e não para comercialização em larga escala de exportação, apresenta-se como elemento determinante da aprovação e confiabilidade dos itens alimentares produzidos e receitas culinárias tão positivamente avaliadas.

Nas comunidades rurais aqui analisadas, de forma análoga a pesquisa de Antonio Greco Rodrigues (1978, p.13), “a maior parte dos animais e plantas considerados como convenientes para a alimentação, procede de produtos da agricultura e da pecuária". O motivo se deve à simbiose que ocorre entre os agricultores familiares e a terra onde moram, plantam, cultivam, colhem, criam e produzem, com confiança sobre a origem de cada um dos itens alimentares que consomem. Assim, “[...] o agricultor mostra um claro orgulho em produzir seu próprio alimento, considerando- 
se em situação de penúria quando se vê obrigado a comprar tudo o que consome." (RODRIGUES, 1078, p.14).

Para compreender o que os produtores rurais entendem por "uma boa alimentação" suas respostas foram agrupadas em noções centrais de explicação. Uma boa alimentação perpassa as ideias de ingerir todas as propriedades fisiológicas para o correto equilíbrio e funcionamento do organismo; o "consumo consciente", acerca do conhecimento sobre a procedência do alimento, ingerindo o máximo possível de produtos do sítio, da terra, radicalmente livres de agrotóxicos, repudiado pelos agricultores familiares, evitando industrializados, indo de encontro ao que Rodrigues (1978, p.14) explana, de que "[...] o alimento industrializado é sempre considerado como menor próprio para o consumo e inferior em qualidade ao alimento natural”.

Outra noção é aquela capaz de matar a fome, de saciar, nos termos nativos, aquela que "enche a barriga"; e ainda aquela conduzida pela ideia de higiene, limpeza e cuidados. Nesta última, revela-se o caráter ritual de preparação da comida, quando se manifestam cuidados com a boa disposição em cozinhar, valendo-se de carinho, em um ambiente limpo e seguro, sem que o impuro e o perigo se façam presentes (DOUGLAS, 1966).
A autora Mary Douglas em seu livro Pureza e Perigo (1966) explana que o conceito de impureza está intrinsecamente ligado ao valor de desordem. Refletindo na análise das respostas feitas pelos entrevistados, os argumentos que mais se repetiram foram na atribuição de limpeza, higiene, amor e carinho na hora do preparo dos alimentos.

Com uma pluralidade de sentimentos, o preparo da alimentação pode expressar tanto a sensibilidade como a frieza do indivíduo que apronta a comida. A questão do zelo, de tratar o alimento com carinho, montar com amor, pode revelar, em seu produto final, a entrega do indivíduo à este ritual.

Observa-se nitidamente também a distinção de composição de cardápios em conformidade com o momento apropriado para preparação de receitas culinárias e o seu encaixe na ideologia alimentar do grupo. Assim, foram encontradas diversas respostas para a justificativa de frequência no preparo de comidas específicas. Muitas são feitas apenas esporadicamente, devido ao seu procedimento dispendioso ficam para os finais de semana. Outras são preparadas em função dos filhos, genuínos apreciadores de receitas específicas, quando se sua ausência, essas receitas ficam esquecidas.

As comidas possuem seu tempo apropriado, algumas são preparadas com 
maior frequência, aparecem cerca de duas ou três vezes ao mês; na ocasião de datas especiais para a família; ou aquelas preparadas em função de visitas, pratos culinários bem aceitos e aprovados por unanimidade; receitas específicas dos finais de semana, e para estas, o destaque das refeições de domingos, dia de maior importância ao que se come; ou pratos culinários preparados sempre a pedido de um integrante da família, destacando-se os pedidos dos filhos, do marido, atendidos prontamente. Esses pedidos são fundamentais para o planejamento do cardápio do dia e revelam um cuidado ainda maior pelo processo de preparação da comida.

As explicações atribuídas para as receitas que ao longo do tempo se capitularam ou transigiram são múltiplas. Entre elas, a dificuldade de encontrar itens específicos utilizados no passado, impossibilitando preparos de receitas reproduzidos fielmente, enquanto dispõem de um ingrediente, pode faltar outro.

A forma rudimentar de conservação dos alimentos no passado, que duravam pouco tempo, ajuda a justificar a capitulação, ou transigência, no sentido de mudarem as receitas desses pratos, ou mesmo de cessarem suas preparações, uma vez que da forma rústica de conservação surgia a necessidade de fazer seu aproveitamento máximo. Por exemplo, as frutas, a fim de não perdê-las, eram aproveitadas sob a forma de licor e doces em conserva.

Outra explicação, embora menos frequente, para receitas que capitularam é remetida à autoria legítima de uma só pessoa, geralmente mãe ou avó, sendo a sua reprodução por outra pessoa incomparável à receita originalmente preparada. Isso se traduz, nas palavras dos informantes, por " $a$ receita era da mãe, nunca ninguém acertou 'a mão' e desistiu", ou ainda "ninguém faz igual à mãe, eu tentei, outros tentaram, mas não fica igual".

Quando os filhos constituem sua própria família e saem da casa dos pais, as tradições permanecem nesta apenas em virtude da visita dos filhos. A comida nostálgica então é preparada com o intuito de agradar aos filhos, reviver suas memórias gustativas, perpetuando receitas e pratos culinários tradicionais. No cotidiano, todavia, na ausência dos filhos, tais receitas tendem a serem postergadas, deixam de serem preparadas com o rigor de antes, e a praticidade entra em voga como o grande determinante da composição do cardápio alimentar.

O uso de fogões a lenha também vem diminuindo ao longo do tempo e hoje já é apontado como uma explicação para o desaparecimento de receitas ou mudança em 
suas formas de preparo, fator determinante para a alteração e desprestígio de muitos pratos. Ele era o responsável por garantir sabores, consistências e temperaturas de cozimento específicas, que garantiam as virtudes da comida. Apesar de sua menor recorrência, os fogões à lenha ainda mantêm o seu valor nas respostas nostálgicas dos entrevistados, reconhecido como o único capaz de conferir melhor sabor e cozimento à pratos e receitas culinárias.

A categorização dos alimentos por classe social, em típicos de uma situação de dificuldade financeira ou típicos de uma situação de fartura, apresenta-se como outro motivo que leva à retaliação de um prato culinário. Nas comunidades rurais estudadas o fenômeno ocorre pela ascensão social da família.

Como exemplos, a farofa de banana frita com mandioca era preparada para a hora do lanche, refeição intermediária entre as duas principais refeições do dia, pois trazia saciamento e energia para o trabalho rural, quando os integrantes da família não podiam consumir qualquer tipo de pão; o ovo frito é outro alimento atribuído à situação de dificuldade e escassez, deixou de ser consumido no almoço dos pequenos produtores porque hoje já possuem outros recursos e consomem carne diariamente.
Outra justifica está na substituição de receitas por outras, geralmente mais práticas. Observa-se, como ilustração, o frango caipira com macarrão caseiro, prato tradicional do final de semana, passando por um processo de redenção ao tempo para a lasanha, que vem substituindo-o progressivamente e aparece citada por $15,5 \%$ dos entrevistados, como a especialidade da família. À esta explicação, articula-se o fator de que a praticidade necessária aos dias de hoje vem sendo determinante para a composição do cardápio.

A memória não se trata de um elemento individual, exclusivamente. Ela possui também dimensões coletivas, que são sociais e a partir destas é que a memória individual vai se constituindo e sendo apropriada pelo indivíduo. Esta afirmativa advém da seguinte ponderação de Michael Pollak: "Vale dizer que a memória e identidade podem perfeitamente ser negociadas, e não são fenômenos que devam ser compreendidos como essências de uma pessoa ou de um grupo." (POLLAK, 1992, p.5)

Com o advento da industrialização, as diferentes sociedades ao longo do mundo passaram por mudanças tecnológicas e mudanças nas relações de produção e de trabalho, no preparo de alimentos especialmente. Fogões à lenha, colheres de pau, pilões de barro ou de madeira bruta, latas 
de alumínio usadas para conservação da carne, caçarolas, tachos e caldeirões, cuias e louças de cerâmica, contam narrativas de um período histórico onde a tecnologia e a globalização ainda não tinham ampliado em demasia seus domínios sobre os utensílios de procedimentos culinários (SIMÕES, 2008). Conforme explana Rodrigues:

O alimentar-se está sempre ligado a um sistema de proibições e recomendações, ou seja, a um conjunto de regras que regulamenta a possibilidade de utilização de certos alimentos, uma vez que esta utilização fundamenta-se muito mais em regras e símbolos sociais que nas necessidades biológicas de nutrição." (RODRIGUES, 1978, p.50).

Assim, verifica-se que a crescente incorporação de tecnologias também é responsável e contribui para a mudança de muitos dos hábitos alimentares, como por exemplo, a conservação das carnes e o sovamento de massas de pão, hoje passadas em cilindro elétrico.

\section{CONCLUSÃO}

A gravidade do fenômeno social da alimentação para os produtores rurais de Pirapitinga, Marajó e Santa Rita, faz com que o plantio, o preparo e o cozimento dos alimentos ocorram de forma altamente ritualizada, exigindo controle e conhecimento sobre toda série de etapas e de ações sucessivas. Assim sendo, as receitas culinárias e pratos típicos são considerados instrumentos identitários e de agregação dos laços locais e regionais, reafirmando Moreira (2010), de que a alimentação revela a estrutura da vida cotidiana, do seu núcleo mais íntimo e mais compartilhado.

Receitas antes trabalhosas, demoradas, vêm sendo substituídas por novas tecnologias, que possibilitam conservar e preparar os alimentos de maneira mais prática e com menor gasto de tempo. $\mathrm{Na}$ visão dos informantes, essas receitas: "Vem sendo substituidas por coisas melhores". Outro exemplo citado pelos entrevistados e que ilustra tal ressignificação, pode ser o uso do cilindro elétrico para preparar massas, mais prático e menos oneroso ao preparo dos alimentos.

Embora o fator cultural seja determinante na seleção dos hábitos alimentares, trata-se de um fenômeno complexo e existem também elementos vinculados à produção de alimentos em escala mundial, por isso as causas do desaparecimento de algumas receitas culinárias devem ser verificadas em profundidade, de acordo com a cada realidade 
e continuam a oferecer um intrigante campo de investigação.

A prerrogativa de que a fixação da ideologia alimentar está diretamente ligada à tradição oral e à experiência pessoal é comprovada nas comunidades rurais pesquisadas, onde a memória coletiva da rotina e os hábitos perpetuam o estilo de conduta da geração anterior até a atualidade.

Os primeiros ensinamentos adquiridos quanto à culinária se renovam em uma tradição que está cerceada na figura feminina, geração após geração, bem como outras tarefas da produção rural distribuídas por gênero, e valores sociais compartilhados quanto às "regras de hospitalidade" e "regras de etiqueta".

Comidas consideradas tradicionais estão vinculadas a lembranças coletivas, ou seja, à pratos culinários associados à uma ocasião ou a pessoas em um reservatório de memórias gustativas que são familiares.

\section{REFERÊNCIAS}

ALTMANN, R. Perspectivas para a agricultura familiar: horizonte 2010. Florianópolis: Instituto Cepa/SC, 2002.

BARBOSA Lívia Horizontes Antropológicos, Porto Alegre, ano 13, n. 28, p. 87-116, jul./dez. 2007

BARDIN, L. Análise de conteúdo. Lisboa: Edições 70, 1979.
LEVI-STRAUSS, Claude. Anthropologie structurale deux (1973, Structural

Anthropology, Vol. II, trans. Monique Layton, 1976)

DOUGLAS, M. Pureza e perigo. Lisboa: Edições 70, 1966.

FISCHLER, C. L'homnivore. Paris: Poche Odile Jacob, 2001.

MINTZ, S. W. Comida e antropologia: uma breve revisão. Revista Brasileira de Ciências Sociais, v.16, n.47, p.31-41, out. 2001. http://dx.doi.org/10.1590/S0102$\underline{69092001000300002}$

MOREIRA, S. A. Alimentação e comensalidade: aspectos históricos e antropológicos. Cienc. Cult., São Paulo, v.62, n.4. 2010.

POLLAK, M. Memória e identidade social. Estudos Históricos - teoria e história, Rio de Janeiro, v.5, n.10, 1992.

RODRIGUES, A. G. Alimentação e saúde: um estudo de ideologia da alimentação. 1978. Dissertação (Mestrado) - Universidade de Brasília, Brasília - DF.

SARTI, C.; DUARTE, L. F. D. (Orgs.) Antropologia e ética: desafios para a regulamentação. Brasília: ABA, 2013.

SIMÕES, R. S. Dona Benta - comer bem: uma fonte para a história da alimentação (19402003). 2008. Dissertação (Mestrado) Universidade de São Paulo, São Paulo - SP.

SOUZA, J. B. L. et al. Atuação da incubadora de empreendimentos econômicos solidários da Universidade Estadual de Maringá com produtores da agricultura familiar. In: CULTI, M. N. Incubadora universitária de empreendimentos solidários: aspectos conceituais e práxis dos processos de incubação. Maringá: Cauiás, 2011. 
TEMPASS, M. C. Antropologia e comida. In: ASSIS, V. S. (Org.). Antropologia, cultura e educação. Maringá: Eduem, 2005.

Recebido para publicação em 19/08/2014

Revisado em 28/08/2014

Aceito em 03/09/2014 